\title{
DOCUMENTAÇÃO
}

\section{Documentação no Campo das Ciências Sociais}

\author{
Edson Nery da Fonseca $\left({ }^{\star}\right)$
}

A

organização de um centro de documentação, no campo das ciências sociais, apresenta problemas complexos, que nos levam a pensar na conhecida frase de Eça de Queiroz: "tenho o processo, falta-me a tese."

É relativamente fácil esboçar o plano de um centro de documentação. Sabemos todos que um órgão dessa natureza deve reunir, organizar e difundir informações. Sabemos que essas atividades são realizadas, em sintese, por serviços de biblioteca, bibliografia e reprografia. De modo geral, essa estrutura é a mesma, quer se trate de documentação em ciências exatas ¿ naturais ou sociais, embora as peculiaridades da literatura de cada ciência determinem algumas diferenças de detalhe.

No caso das ciências sociais, a situação se complica em face principalmente da imprecisão conceitual - haja vista, por exemplo, a multiplicidade de conceitos de cultura, salientada, entre ou^ tros, por T. S. Eliot $\left({ }^{3}\right)$ - e da inter-relação que as caracterizam. Numa época em que as chamadas classificações hierárquicas dos conhecimentos humanos vêm sendo crescentemente sub.3tituidas pela indexação em tôrno de palavras-chaves, a tmprecisão conceitual coloca para a documentação problemas complexos. T'ambém da inter-relação entre as ciências sociais decorrem para a documentação problemas quase insolúveis de dispersão. A dispersão, como se sabe, consiste na ocorrência de artigos especializados num determinado campo em revistas especializadas em outros campos e nas de cultura geral. Este fenômeno é uma verdadeira "pedra no meio do caminho" tanto dos pesquisadores como dos documentalistas. Pois para uns e para outros, o exame das revistas especializadas torna-se altamente insuficiente, em face da dispersão dos artigos em revistas de outras especializações.

Temos, portanto, o processo - inclusive processo adaptado ao caso específico das ciências sociais - mas faltam as teses, ou melhor, subsiste uma indecisão entre as teses que surgem como

(*) Professor de Bibliografia da Universidade de Brasília e Bibliotecário da Câmara dos Deputados. 
soluções para o problema da documentação em ciências sociais e da necessidade de uma coordenação entre instituições nela interessadas.

Essas teses seriam ( $\left.{ }^{1}\right)$ um só órgão, como o Centro Latino. Americano de Pesquisas em Ciências Sociais, faria a documentação em ciências sociais de tôda a América Latina; ${ }^{(2)}$ vários órgãos fariam a documentação de campos específicos das ciências sociais em tôda a América Latina; ${ }^{3}$ ) vários órgãos fariam a documentação de campos específicos das ciências sociais em determinados paises do continente.

A dificuldade de opção por uma dessas soluções resulta da falta de conhecimento pormenorizado - pelo menos por parte do autor dêste documento - da realidade latino-americana em matéria de pesquisas em ciências sociais.

Impõe-se, assim, inicialmente, a elaboração de uma série de instrumentos básicos que permitirão saber: (1) quais as revistas latino-americanas que divulgam artigos de interêsse para a $\mathrm{An}$ tropologia, Ciência Politica, Demografia, Economia, Educação, Psicologia Social, Relações Internacionais e Sociologia; $\left({ }^{2}\right)$ quais as instituições latino-americanas, governamentais ou privadas, que promovem pesquisas e/ou congregam pesquisadores nos mencionados campos; $\left({ }^{3}\right)$ quais os cientistas sociais lantino-americanos; $\left({ }^{4}\right)$ quais as pesquisas em andamento a em projeto; $\left({ }^{5}\right)$ quais as instituições de ensino de ciências socials; $\left({ }^{6}\right)$ quais as teses apresentadas às universidades latino-americanas no campu das ciências sociais; $\left({ }^{7}\right)$ quais os congressos nacionais e internacionais de ciências sociais; $\left({ }^{8}\right)$ quais as obras de referência latinoamericanas no campo das ciências sociais; $\left({ }^{9}\right)$ quais as bibliotecas, arquivos e museus lantino-americanos de interêsse para as
ciências sociais.

No caso das revistas, dois inventários são necessários: um exaustivo e outro seletivo. Para a seleção, deve-se levar em conta o critério estabelecido pelo Grupo de Trabalho para a Seleção de Revistas Cientificas Latino-Amrericanas, criado pelo Centro de Cooperação Científica da UNESCO para a América Latina. $\left({ }^{2}\right)$ Essa inventariação permitirá um estudo em profundidade das publicações periódicas latino americanas no campo das ciências sociais, contendo sugestões de fusão, maior delimitação de campos e até de extinção sumária.

Sòmente depois de conhecida a situação real, através dos levantamentos sugeridos, poder-se-á escolher a politica a ser adotada em matéria de documentação em ciências sociais no âmbito
latino-americano.

Concomitantemente com o preparo dêsses inventários, deve - Centro Latino-Americano de Pesquisas em Ciências Sociais estudar e adaptar às ciências sociais o Código de boa prática em 
matéria de publicações cientificas, elaborado conjuntamente por quatro respeitáveis organizações internacionais - Federação Internacional de Documentação (FID), Conselho Internacional de Organizações Científicas (ICSU), Federação Internacional de Associações de Bibliotecários (FIAB) e Organização Internacional de Normalização (ISO) - e aprovado pela Comissão Consultiva Internacional de Bibliografia, Documentação e Terminologia da UNESCO, no ano de 1961.

Trata-se de documento destinado especialmente às ciências exatas e naturais e à tecnologia, não podendo ser totalmente aplicado às ciências sociais, sem a adaptação aqui sugerida e cuja necessidade o Código expressamente salienta no preâmbulo.

Não se diga que cogitações dessa natureza estão fora do campo de ação dos documentalistas. Para ser realmente eficaz, a documentação não pode limitar-se a organizar a coleçãc de documentos em bibliotecas e sua difusão por meio de bibliografias, indices, resumos, reproduções, etc. Durante muito tempo tratou-se de uniformizar os processos de coleção difusão, sem atentar para o fato de que êsses processos estavam sendo entravados pela falta de uniformização na produção dos documentos, devendo-se entender como tal a elaboração, impressão e edição.

Hoje, todos reconhecem a necessidade de racionalizar os velhos meios de comunicação entre os cientistas. Alguns chegam a sugerir a substituição sumária das revistas científicas pela publicação avulsa dos artigos. Uma coisa é certa: os autores e editôres de trabalhos científicos não têm mais o direito de apresentar êsses trabalhos de acôrdo com sua imaginação, seus caprichos ou suas idéias próprias a respeito de técnica editorial e arte gráfica. A produção bibliográfica em larga escala exige uma racionalização, sob pena de ficar inaproveitada.

É significativo que tenha sido um filósofo e não um documentalista quem mais enfatizou a necessidade de se "organizar coletivamente a produção do livro." E dando uma resposta antecipada aos que se insurgem contra a racionalização do trabalho intelectual em nome da imaginação criadora ou da liberdade de criação, assim se exprimiu Ortega y Gasset, em 1935: "No se venga com la tontería de que tal organización sería atentatoria a la libertad. (...) La organización colectiva de la producción libresca no tiene nada que ver con el tema de la libertad, como no tiene nada que ver con él na necesidad que se ha interpuesto de reglamentar la circulación en las grandes urbes."

A comparação entre informação científica e comunicação urbana é perfeita. Assim como os motoristas devem conhecer e respeitar as normas de trânsito, sob pena de desorganizá-lo, os autores e editôres devem conhecer e respeitar as normas internacionais da informação científica, a fim de que ela possa cirzular racionalmente e ser internacionalmente aproveitada. 
A desorganização ora reinante em todos os campos da informação científica - mas principalmente nos das ciências sociais, porque os das ciências exatas e naturais estão, há vários anos, procurando estudá-la, alguns já tendo cncontrado soluções adequadas - prejudica de modo considerável o trabalho dos centros de documentação. Por isso os bibliotecários mais conscientes e os chamados documentalistas estão empenhados em orientar a produção bibliográfica, em vez de se limitarem a colecioná-la e difundi-la: para que os trabalhos de coleção e difusão se tornem mais eficientes.

Em apoio da atribuição dessa tarefa aos bibliotecários também se manifestou OrTEga y GASSET, ao escrever: "Hasta ahora se ha ocupado principalmente del libro como cosa, como objeto material. Desde hoy tendrá que atender al libro como función viviente: habrá de ejercer la policia sobre el libro y hacerse domador del libro enfurecido. (...) En esta dimensión de su ofício imagino al futuro bibliotecario como un filtro que se interpone entre el torrente de los libros y el hombre."

O conhecido físico inglês J. D. Bernar., tratando do mesmo assunto, sugere "a very much closer relation between the librarian and the research worker than has existed in the past. (...) a closer relation between the function of the librarian and the function of the publisher, both of periodicàls and of books." $E$ explica: "In fact the whole of scientific communications between scientists, and between them and the technical and lay public, is one unified subject. The separation between the business of producing printed matter, storing it and distributing it, has been the curse of the learned world long before the printing press was invented. But what was tolerable when it was difficult for the learned man to find enough that was worth him while to read, has now become, under the enormous mass of published material, a totally intolerable position, one whose continuance threatons the whole progress of knowledge." (1)

O Centro Latino-Americano de Pesquisas em Ciências Sociais deverá assumir papel importante na coordenação sugerida por BERNAL - entre o produtor, o organizador e o consumidor da documentação em ciências sociais - e na organização preconizada por ORTEGA. Essa coordenação e a concomitante organização da produção bibliográfica são fatôres básicos para o funcionamento eficaz de um serviço de indexarsão e resumo dessa produção.

Centralizado ou descentralizado, conforme se escolha uma das soluções supra indicadas, sua eficiência será tanto maior quanto mais coordenada e organizada seja a publicação - avulsa e periódica - da literatura de ciências sociais. 


\section{REFERENCIAS BIBLIOGRAFICAS}

\section{A - DOS TRABALHOS CITADOS}

(1) BERNAL, J. D. Information service as an essential in the progress of science. Report of Proceedings of the 20th Conference of Aslib, London, 1945, págs. 20-24. Apud Coblans, Herbert. The communication of information. Inc.: Goldsmith, Maurice \& Mackay, Alan, ed. The science of science. London, Souvenir Press, 1964, págs. 93-101.

(2) Centro de Cooperação Científica da UNESCO para a América LATINA. Grupo de Trabalho para a Seleção de Revistas Cientificas Latino-Americanas. Informe final. Informaciones sobre Documentación e Información Cientificas (Montevidéu) 3 (2): 5-27, jul./set. 1964.

(3) ELIOT, Thomas Stearns. Notes towards the definition of culture. London, Faber and Faber (1948), 124 págs.

(4) Ortega y Gasset, José. Misión del bibliotecario. In: El libro de las misiones (5. ed.) Buenos Aires, Espasa Calpe Argentina (1950), págs. 11-150 (Colección austral, 101).

B - DE TRABALHOS SÔBRE DOCUMENTAÇÃO EM CIÊNCIAS SOCIAIS

(1) Berelson, B. \& Smith, B. L. Propositions en vue de l'établissement d'une bibliographie et d'un système de comptes rendus analytiques unifiés pour les sciences sociales. In: UNESCO. Departamento de Ciências Sociais. Inventaire raisonné des services périodiques de documentation des sciences sociales. Paris (1951), págs. 41-50.

(2) BURKHARDT, Frederick. Inter-American scholarly communication in the humanities and social sciences. American Political Science Review (Menasha, Wis.) 54 (3) : 835-839, Sep. 1960.

(3) Fosketr, D. J. Classification and indexing in the social sciences. London, Butterworths, 1963. X +190 págs.

(4) ILENRY, Mildred I. Some problems of bibliographie control in the social sciences. Special Libraries (New York) 41 (3): $87-89$ e 110-111, Mar. 1950.

(5) KYLE, Barbara. Current documentation topics and their relevance to social science literature. Revue Internationale de la Documentation (La Haye) 24 (3): 107-117, Aug. 1957. Existe tradução em português:

(5-A) Problemas atuais da documentação e sua importâncla para a bibliografia das ciências sociais. Trad. de Maria Amélia Porto Migueis. Revista do Serviço Público (Rio de Janeiro) 83 (2): 150-170, maio 1959.

(6) KYLE, Barbara. Towards a classification for social science literature. American Documentation (Washington) 9 (3): 168-183, Mar. 1958.

(7) KYLE, Barbara. Some further considerations on the application to social science material of up-to-date methods of bibliographical control and information retrieval. Journal of Documentation (London) 14 (4): 190-196. Dec. 1958.

(8) KYLE, Barbara. Ventajes e inconvenientes de los diversos sistemas de classificación aplicables a las ciencias sociales. Boletin de la UNESCO para las Bibliotecas (Paris) 14 '(2): 54-60, mar./abr. 1960. 
(9) KyLE, Barbara. The Universal Decimal Classification; a study of present position and future developments, with particular attention to the humanities, arts and socfal sciences. Unesco Bttletin for Libraries (Paris) 15(2): 53-69, mar./apr. 1961.

(10) LEWIS, Peter $R$. The literature of the social sciences; an introductory survey and guide. London, Library Association, 1960. xx+ $222 \mathrm{p}$.

(11) Meyriat, Jean. Rapport sur les principes généraux du travail bibliographique international. Paris, UNESCO, 1957. 39 p. (UNESCO/ CUA/82).

(12) Meyriat, Jean. Etude des bibliographies courrantes des publications officielles nationales. (Paris) UINESCO (1958), 260 p. (Manuels bibliographiques de l'Unesco, 7).

(13) Mukerjee, A. K. Human sciences of Anthropology, sociology and psychology and Sociology social psychology and allied topics. In: Annotated guide to reference materials in the human sciences. London. Asia Publishing House, 1962, p. 3-5 e 175-176.

"... the trend of modern research in the Human Sciences has been drifting towards the integration of the sciences of anthropology, sociology and psychology... It is therefore natural that these sister disciplines would co-operate and converge both in theory and practice" (p. 3).

(14) Olrvos, Luis. Publicaciones que contienen datos bibliograficos sobre las ciencias sociales en America Latina. Revista Interamericana de Ciencias Sociales (Washington) 1(3): 407-414, 1962.

Smith, B. L., colab. Ver Berelson, B. \& Smith, B. L.

(15) TAEUBER, Irene B. The social sciences: characteristics of the literature, problems of use, and bibliographic organization in the field. In: Shera, Jesse H. \& Egan, Margaret E., ed. Bibliographic organization... Chicago, University of Chicago Press, 1951, p. 127-139.

(16) UNESCOO. Comitê Internacional para a Documentação de Ciências Sociais. Liste mondiale des périodiques spécialisés dans les sciences sociales. 2. ed. rev. et augm. Paris, UINESCO, 1957, 210-p.

(17) União Pan-Americana. Departamento de Assuntos Culturais. Guia de instituciones $y$ sociedades en el campo de las ciencias sociales. 2. pt.: América Latina. Washington, 1950. 126 f. mimeogr. (Publicaciones de la Oficina de Ciencias Sociales. Guias de instituciones, II).

Necessita de atualização. Não incluị o Centro, por exemplo, nem o Instituto Joaquim Nabuco de Pesquisas Sociais.

(18) University of Chicago. Graduate Library School \& Division of the Social Sciences. Bibliographical services in the social sciences. $L i$. brary Quarterly (Chicago) 20(2): 79-100, Apr. 1950.

ANEXO 1

\section{CODIGO DE BOA PRATICA EM MATERIA DE PUBLICAÇOES CIENTIFICAS}

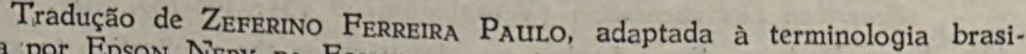
leira por Edson Niery da Fonseca.

A Comissão conjunta FID/ICSU/IFLA/ISO (1), criada e reunida para examinar os meios de promover uma ação internaciorfal eficaz no sentido de

(1) FID: Fédération Internationale de Documentation; ICSU: International Council of Scientific Unions; IFLA: Intermational Federation of Library Associations; ISO: International Organization for Standardization. 
melhorar a atual situação da informação cientifica, considera que a falta de disciplina, livremente consentida, em matéria de redação e de publicação de informações cientificas é uma das principais causas do aumento inútil do volume de documentos publicados, das despesas feitas para os imprimir, para os resumir, para os referenciar e para os encontrar.

Em conseqüência, a Comissão, por proposta do secretário do Departamento de Resumos (Résumés Analytiques) do ICSU, redigiu sob uma forma tão breve quanto possivel um texto estabelecendo as regras que deverão constituir uma evidente obrigação moral para todo autor de publiçação cientifica e todo redator de periódico científico.

O texto, que se aplica, especialmente, às ciências exatas e naturais e à tecnologia, compõe-se de quatro partes. A primeira estabelece que um resumo corretamente redigido, e de que o autor é o próprio responsável, deve preceder tôda a memória cientifica. A segunda define três categorias de textos cientificos originais - memória cientifica; comunicações provisórias ou notas prévias; exposições sôbre o estado atual do problema - demonstrando o que os distingue e sugerindo ser obrigação de todo autor indicar a qual destas três categorias pertence o texto que se propôe publicar. A terceira parte refere-se à redação dos textos cientificos e estabelece, especialmente, a obrigação moral para todo o autor de assinalar qualquer duplicação ou qualquer omissâo nas partes significativas do texto publicado.

Por diversas vêzes, nestas três primeiras partes, lembra-se que é de primordial importância para o futuro da documentação cientificca a adoção de normas internacionais e universais que permitirão conseguir: um método único de redação de sinopses; um código único para abreviação dos títulos dos periódicos cientificos; um código único para a maneira e a ordem por que devem ser feitas as citações bibliográficas numéricas; um código único de simbolos e abreviaturas de têrmos técnicos; um código único para a transliteração dos caracteres de um alfabeto para outro e regras comuns para a preparação de vocabulários técnicos e para a sua equivalência multilingüe.

A Comissão está convencida de que o sucesso destas normalizações será a única maneira de tornar possivel o emprêgo de processos automáticos para a classificação das informações e das publicações cientificas e para as pesquisas que permitam estabelecer ràpidamente bibliografias retrospectivas.

A Comissão foi criada para dar exemplo de colaboração e acabar com a dispersão de esforços (a começar pelos textos internacionais múltiplos e por vêzes contraditórios), tendo elaborado o texto em questão e incumbido a ISO, em cooperação intima com todos os outros organismos que ela representa, de promover a conclusão rápida daquelas normas $(2)$ para as quais um acôrdo geral não foi ainda conseguido.

A quarta parte do texto visa os redatores-chefes de periódicos e publicações cientificas e considera sua obrigação moral verificar se os autores conhecem e adotam as disposições que lhes dizem respeito. Recomenda, também, a êstes redatores-chefes a autorização da reprodução dos resumos dos autores. A Comissão não considerou necessário lembrar-lhes, pormenorizadamente, as recomendações da normalização internacional relativas, especialmente, à apresentação dos periódicos e livros, pois elas constituem um dos elementos de base dos seus conhecimentos profissionais.

O texto adotado, unânimemente, pela Comissão, foi submetido à Comissão Consultiva Internacional de Bibliografia, Documentação e Terminologia da UNESCO, por ocasião da sua $1^{\text {* }}$ reunião em Paris, de 25 a 29 de setembro de 1961. Esta Comissáo, que o aprovou igualmente, foi de opinião que o Código, concebido para as ciêníias exatas e naturais e para a tecnologia,

(2) Ver, no anexo II, a lista das "Recomendações" pertinentes da ISO. 
não poderia ser aplicado às ciências sociais e às ciências humanás sem prévio exame pelas organizações internacionais não governamentais especializadas em tais dominios.

A UINESCO publica e difunde o "Código de boa prática em matéria de publicações cientificas", persuadida como está de que o acatamento das regras dêste Código permitirá acelerar a ordenação da documentação cientifica, aumentará o valor das informações que ela contém e reduzirá as enormes despesas dos centros de documentação cientifica e técnica de todos os países.

\section{CODIGO DE BOA PRÁTICA EM MATÉRIA DE PUBLICAÇOES CIENTIFICAS}

\section{A - A sinopse}

1. Todo o texto destinado a ser publicado num jornal ou periódico cientifico ou técnico deve ser acompanhado de uma sinopse redigida pelo
próprio autor.

2. Enquanto se aguard'a uma normalização internacional, a sinopse deve ser redigida de acôrdo com as regras e conselhos reunidos na "Guia para a redação das sinopses", elaborado, impresso, distribuido e periòdicamente revisto pela UNESCO (documento NS/37. D 10 a). (3)

\section{B - NATUREZA DO TEXTO}

3. O autor, ao remeter o original do seu texto à redação do periódico onde o deseja publicar, deverá concretizar, na medida do possivel, em qual das categorias de literatura cientifica êsse texto deve ser classificado: a) Memórias cientificas; $b$ ) Comunicações provisórias ou notas prévias; c) Exposições sôbre o estado atual do problema.

4. Um texto pertence à categoria de "memórias cientificas" quando é redigido de tal modo que um investigador qualificado, suficientemente especializado no mesmo ramo da ciência, seja capaz, a partir sòmente das indicações
fornecidas:

- de reproduzir as experiências e obter os resultados que êle descreve com erros iguais ou inferiores a limite superior especificado pelo autor;

- de repetir as observações e julgar as conclusões do autor; - de verificar a exatidão dàs análises e inferências que levaram o autor
a essas conclusões.

5. Um texto pertence à categoria de "comunicações. provisórias ou notas prévias" quando, embora contribuindo com uma ou várias informações cientificas novas, sua redação não permite aos leitores verificá-las nas condições indicadas no parágrafo 4 .

6. As "exposições sôbre o estado atual do problema" não têm por objetivo divulgar informações científicas novas; reúnem, analisam e discutem informações já publicadas respeitantes a um determinado assunto.

\section{C - REDAÇÃO DO TEXTO}

7. A introdução histórica ou crítica, sempre útil, deve ser tão breve quanto possivel: o autor evitará redigir uma "memória cientifica" como se se tratasse de expor o estado atual do problema.

(3) Ver anexo I. 
8. A sintaxe será tão simples quanto possível. As palavras deveriam poder ser encontradas num dicionário atualizado. Quando esta exigência não puder ser satisfeita, o autor deverá certificar-se de que os neologismos utilizados pertencem ao vocabulário científico e técnico internacional. (4)

9. Na redação do texto, indicar-se-ão os métodos empregados e os resultados significativos. Se, por considerações de propriedade industrial ou de segurança, o autor é levado a limitar as informações que êle descja publicar sôbre o tema de que se ocupa, deverá então o texto ser apresentado como pertencendo à categoria $b$ ) "comunicações provisórias ou notas prévias", e não como uma "memória". Esta é para o cientista uma obrigação moral absoluta. (5)

10. Será feita uma referência explicita a todo o trabalho anteriormente publicado pelo mesmo autor ou por qualquer outro, quando o conhecimento dêsses trabalhos fôr essencial para situar o texto apresentado na evolução cientifica do assunto. Indicar-se-á se essas publicações anteriores constituem duplicação total ou parcial em relação ao texto apresentado.

11. Em nenhum caso se utilizarão comunicações privadas ou publicações de caráter secreto ou de difusão restrita para fornecer argumentos ou provas. (6)

12. O autor, na redação do seu texto, respeitará as normas internacionais relativas à abreviação dos titulos dos periódicos, à ordem das citações bibliográficas, aos simbolos, às abreviaturas, à transliteração, à terminologia c à apresentação dos artigos. Utilizará um sistema coerente de unidades de medidas, que deverá especificar claramente.

\section{D - RECOMENDAÇÕES AOS REDATORES-CHEFES E EDITÔRES DE PERIÓDICOS CIENTÍFICOS}

13. Ao aceitar, para fins de publicação, um artigo científico, o redatorchefe deverá conseguir que o próprio autor indique se o seu texto pertence à categoria a) "memórias cientificas", à categoria b) "comunicações provisórias ou notas prévias", ou à categoria c) "exposições sôbre o estado atual do problema."

14. Ao imprimir o texto aceito, o redator-chefe mencionará antes da sinopse em qual das três categorias o texto deve ser considerado.

15. Ao aceitar o texto cientifico para publicação e enquanto se aguarda a normalização internacional, o redator-chefe assegurar-se-á de que a sinopse,

(4) Recomenda-se a indicação da origem dos neologismos utilizados. No caso de o autor ter sido forçado a criá-los, por si próprio, deverá descrever o processo de formação do neologismo, dando a sua etimologia e definição. Em suma, o autor deverá velar pela não deformação do sentido dos têrmos pertencentes ao vocabulário específico do campo do conhecimento de que se ocupa.

(5) Admite-se ser evidente para todos que em nenhuma publicação se deverá, conscientemente, deformar a descrição dos fatos observados ou dos métodos empregados.

(6) Não é caso para impedir a aiusão a conversas ou a comunicações privadas, mas salienta-se que não se afigura legitimo formular uma afirmação ou chegar à uma conclusão reportando-se a uma simples conversa não verificável.

Consideram-se publicações de difusão restrita as que, gratuitas ou vendidas, não são acessiveis ao público cientifico em geral. 
que deve acompanhar obrigatòriamente o texto, foi redigida de acôrdo com as indicações dadas no "Guia para a redação das sinopses" (of. recomendação A, parte 2 e comentários).

16. Para assegurar, por tôda 'a parte e em todo o tempo, a reprodução livre das sinopses, deve declarar-se expressamente nas páginas editoriais que é autorizada a sua reprodução.

\section{I - GUIA PARA A REDAÇAO DE SINOPSES}

1. Por sinopse compreende-se o resumo de um trabalho cientifico, redigido pelo próprio autor e publicado ao mesmo tempo que o trabalho, depois de examinada pela redação do periódico. (7)

2. O objetivo das sinopses não é apenas facilitar a consulta do periódico que as publica, mas também tornar o trabalho das redações dos periódicos de resumos menos oneroso e mais rápido, contribuindo, assim, para o melhoramento geral dos serviços de documentação cientifica.

3. A sinopse deve recapitular sucintamente os fatos contidos no trabalho e suas conclusões e chamar a atenção para os novos dados do problema. indicando a sua importância. Deve permitir ao leitor - sem tempo para ler tudo - ajuizar, melhor do que sòmente pelo titulo, se o trabalho interessa ou não.

4. Por conseqüência, pede-se aos autores de todos os trabalhos que forneçam, igualmente, uma sinopse de acôrdo com as diretrizes seguintes:

\section{REDAÇÃO}

5. E preferivel usar frases inteiras em vez de uma simples seqüência de titulos. O autor do trabalho deve ser mencionado sempre na $3^{4}$ pessoa. Devem empregar se têrmos geralmente aceitos, e não apenas os de uso particular. As contrações inúteis devem ser evitadas. Presumir-se-á que o leitor tem algum conhecimento do assunto, mas não leu ainda o trabalho. A sinopse deve, portanto, ser compreensivel por si própria, sem que seja necessário reportar-se ao trabalho. (Nunca citará, por exemplo, parágrafos ou ilustrações pelo número que apresentam no texto).

\section{CONTEÚDO}

6. Como o titulo do trabalho é em geral lido como se fizesse parte da sinopse, deve evitar-se que a primeira frase o repita. Se, todavia, o titulo não é suficientemente explicito, a primeira frase indicará o assunto tratado. Regra geral, o inicio da sinopse deveria revelar o objetivo das pesquisas.

(7) Em inglês, o têrmo synopsis foi adotado pela Royal Society de Londres (segundo a recomendação da Conferência de Documentação Cientifica efetuada em 1948 sob os seus auspicios) e pela Conferência Internacional sôbre Resumos Documentais Cientificos promovida pela UNESCO em
1949 . 
7. Por vêzes é útil indicar a maneira como o assunto foi tratado, por têrmos tais como: sucinta, aprofundada, teórica, etc.

8. A sinopse deve indicar os fatos novos observados, as conclusões tiradas de uma experiência ou de um argumento e, se possivel, as novas linhas essenciais das teorias, técnicas, processos, aparelhos, etc.

9. Deve conter o nome de todo o nôvo composto, minério, etc., assim como de todos os novos dados numéricos, tais como uma constante física, etc.; se isso não fôr possivel, deve chamar a atenção sôbre o assunto. E importante mencionar as observações e fatos novos, mesmo que não digam respeito ao assunto principal do trabalho, senão acessòriamente, pois, caso contrário, estas informações poderão passar despercebidas apesar do seu valor eventual.

10. Quando a sinopse indica resultados, deve mencionar o método empregado. Para os métodos novos, o principio básico, o dominio de aplicação e o grau de exatidão devem ser expressos com rigor.

\section{REMISSIVAS, REFERÊNCIAS BIBLIOGRÁFICAS}

is

11. Se na sinopse fôr necessário fazer referência a uma publicação anteriar, esta referência deve ser sempre redigida da mesma forma que no trabalho original. Caso contrário as referências devem ser omitidas.

12. As referêncías bibliográficas relativas a periódicos cientificos devem ser redigidas conforme o uso estabelecido pelo periódico no qual o trabalho aparece. (A Conferência Internacional sôbre Resumos Documentais Cientificos recomendou as regras propostas pela Organização Internacional de Normalização, Comissão Técnica 46, sendo os títulos dos periódicos abreviados da mesma forma que na World List of Scientific Periodicals).

\section{EXTENSÃO}

13. A sinopse deve ser tão concisa quanto possivel. Só excepcionalmente deve exceder de 200 palavras, de forma a poder ser cortada uma vez impressa e colocada sôbre ficlfas de formato $7,5 \mathrm{~cm} \times 12,5 \mathrm{~cm}$.

\section{PUBLICAÇÃo - LÍNGUA E FORMATO}

14. A Conferência Internacional sôbre Resumos Documentais Cientificos recomendou que as sinopses fôssem publicadas numa lingua de grande expansão, seja qual fôr a lingua do trabalho original a fim de facilitar a sua compreensão internacional.

15. A Conferência Internacional sôbre Resumos Documentais Cientílicos recomendou igualmente o uso, seguido por certos periódicos, de reunir tôdas as sinopses de um mesmo fasciculo no verso da capa ou em páginas cujo verso corresponda à publicidade, de forma que se possam cortar e colocar sôbre fichas sem mutilar as páginas do próprio periódico. Para êste fim, as sinopses serão impressas com uma mancha tipográfica de $10 \mathrm{~cm}$, no máximo, a fim de poderem ser colocadas em fichas do formato $7,5 \mathrm{~cm} \times 12,5 \mathrm{~cm}$. 


\section{II - LISTA DAS RECOMENDAÇÕES DA ISO RESPEITANTES A PUBLICAÇÕES CIENTIFICAS}

ISO/R 4-Código internacional para abreviação dos titulos de periódicos. ISO/R 8 - Apresentação de periódicos.

ISO/R 9 - Sistema internacional para a transliteração dos caracteres cirílicos.

ISO/R 18 - Sumário de periódicos ou de outros documentos.

ISO/R 30 - Legenda bibliográfica.

ISO/R 77 - Referências bibliográficas. Elementos essenciais.

ISO/R 214 - Resumos e sinopses.

ISO/R 215 - Apresentação de artigos de periódicos.

ISO/R 233 - Sistema internacional para a transliteração dos caracteres arábicos.

Projeto ISO $n^{\circ} 315$ - Transliteração dos caracteres gregos em caracteres latinos.

Projeto ISO n 379 - Transliteração do hebreu.

ANEXO 2

\section{CRITERIOS PARA LA APRECIACIÓN DE LA CALIDAD DE LAS REVISTAS CIENTIFICAS Y TECNICAS LATINOAMERICANAS}

(Informe del Comité constituido por los doctöres Julio Arends (Venezuela), Juan Manuel Gutiérrez Vázquez (México) y Mario Vianna Dias (Brasil), designado por el Grupo de Trabajo, reunido en Puerto Rico, abril 28 - mayo 1 - 1964).

El Comité designado por el Grupo de Trabajo reunido en San Juan de Puerto Rico, encargado de formular las bases que podrian constituir una aportación para determinar la calidad de una Revista científica e técnica, ha llegado a las conclusiones que se exponen a continuación.

El criterio básico que ha servido al Comitê, es la asignación de un determinado número de puntos por cada uno de los conceptos que deben indicar la calidad de las revistas. En lo que a esto atañe se trata simplemente de un ensayo que se presenta como base para estudios ulteriores del problema.

1. CALIDAD DE LOS ARTícuLOS

La calidad de los articulos debe de ser considerada en primer término para juzgar una revista cientifica o técnica.

Deben ser descartadas aquellas revistas que no tengan por lo menos un $50 \%$ de artículos de buena calidad. Para determinar ese porcentaje debe tomarse como punto de partida el año 1960. Deberá exigirse un porcentaje aun mayor cuando asi lo justifique el alto desarrollo alcanzado en Latinoamérica por la respectiva especialidad que refleja la revista.

Se asignarán 20 puntos a las revistas que, desde 1960 hasta hoy, hayan publicado un $50 \%$ de buenos artículos. Por cada 10\% suplementarios se le asignarán cuatro puntos. 


\section{PRESENTACIÓN DEL MATERIAL}

La observancia de las normas internacionales, la correcta confección y utilización de referencias bibliográficas, resúmenes analíticos, así como de cuadros estadisticos e ilustraciones, y en general todo lo que atañe a la adecuada presentación del material, merecerá 5 puntos adicionales.

\section{DURACIÓN}

Se ha asignado un punto por cada dos años de existencia de la revista.

\section{REGULARIDAD DE APARICIÓN}

Se debe deducir un punto por cada retraso mayor de 6 meses.

\section{PERIODICIDAD}

Las revistas que publican 2 entregas al año no tienen ninguna puntuación. $\mathrm{Si}$ dichas entregas se reducen a una sola, se le deducirán 5 puntos. Si al contrario, publica varias más, se le asignarán 2 puntos por cada entrega adicional.

\section{ACEPTACIÓN DE COLABORACIONES}

$\mathrm{Si}$ una revista ha venido publicando regularmente desde el año 1960 inclusive, colaboraciones nacionales de personas ajenas al instituto o asociación a los que sirve de órgano de difusión, se le asignarán 5 puntos. Si además publica regularmente colaboraciones de personas no nacionales, se le asignarán 10 puntos.

\section{ESPECIALIZACIÓN}

Si la revista abarca una rama cientifica, se le asignarán 5 puntos, y si se circunscribe a una especialidad, se le asignarán 10 puntos.

\section{INCLUSIÓN EN REVISTAS EXTRANJERAS}

Por cada publicación extranjera dedicada a resúmenes, referencias biblio. gráficas, contenidos, etc., que la incluya, se le asignarán 5 puntos.

\section{MENCIÓN EN EL SCIENCE CITATION IÑEEX}

Por cada dos referencias a la revista se le asignará un punto.

\section{ENVIO A BIBLIOTECAS}

Si bien envio a bibliotecas no es un dato de gran significación, él representa sin embargo el esfuerzo del o de los editores por hacer conocida y útil una revista. Por tanto, el Comité recomienda que por cada diez bibliote. cas que reciban la revista, se le asigne un punto y sugiere que para verificar este dato, utilicen las estadisticas publicadas en el Chemical Abstracts ut otras similares.

Se adjuntan dos tablas. La Tabla I contiene datos en forma simplificada y la Tabla II se refiere a la escala de apreciación para valorar una revista de acuerdo a estos parámetros. Las que obtengan una puntuación menor de 25 son deficientes; de 26 a 60 , regulares; de 61 a 80 , buenas; de 81 a 100 , muy buenas, y mas de 100 , excelentes. 
TABLA I

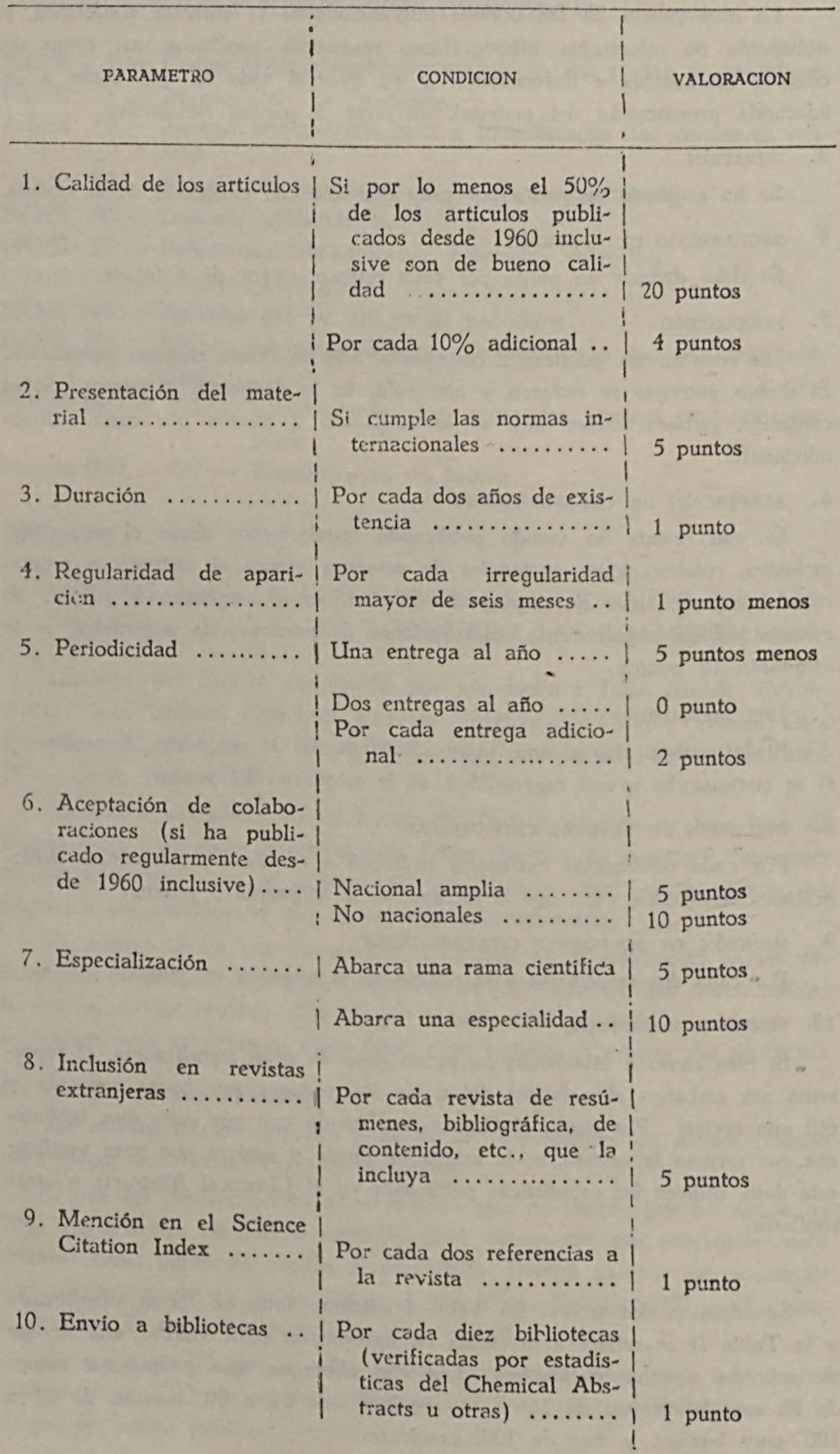




\section{TABLA II}

ESCALA DE APRECIACION

(Para valorar una revista analizada según los parámetros de la Tabla I)

$\begin{aligned} \text { Puntuación } & \text { Clasificación } \\ <25 & \text { Deficiente } \\ 26-60 & \text { Regular } \\ 61-80 & \text { Buena } \\ 81-100 & \text { Muy buena } \\ >100 & \text { Excelente }\end{aligned}$

